\title{
Experimental comparative study of reactive powder concrete: mechanical properties and the effective factors
}

\author{
Eyad Kadhem ${ }^{1, *}$, Ammar Ali ${ }^{1}$, and Sameh Tobeia ${ }^{1}$ \\ ${ }^{1}$ Building and Construction Engineering Department, University of Technology, Baghdad, Iraq
}

\begin{abstract}
Reactive Powder Concrete (RPC) is a type of ultra-high performance concrete, this dense composite material generally characterized by high cement content, high durability, low porosity, low water/cement ratio and in most cases contains steel fibers as new types of concrete appears, further investigation for their mechanical properties are needed. This work aims to give a better understanding of RPC behavior by deriving formulas to calculate the modulus of elasticity and the splitting tensile strength in relation with compressive strength and steel fibers content. This study is based on data obtained from the experimental investigation done in this work and from others pervious works. The parametric study is based mainly on the silica fume content which is used in four different ratios $(12 \%, 15 \%, 20 \%$ and $25 \%)$, the use of micro steel fibers $15 \mathrm{~mm}$ in length, $0.2 \mathrm{~mm}$ in diameter and aspect ratio of 75 added in ratios of $(0 \%$, $1 \%, 1.5 \%$ and $2 \%)$, and water/cement in ratios of $(16 \%, 18 \%, 20 \%$ and $22 \%)$, respectively. The proposed equations show a better behavior in comparison to some available equations that were used in the estimation of modulus of elasticity and splitting tensile strength of reactive powder concrete, the coefficient of variation for the proposed equations (COV) decrease to $10.677 \%$ and $10.455 \%$ respectively.
\end{abstract}

\section{Introduction}

In order to make a better understanding of concrete (plain concrete, reinforced concrete and prestressed concrete) behavior and to ensure a more accurate concrete structural design, the modulus of elasticity which represents a fundamental factor for the elastic deformation prediction of concrete members should be studied. The splitting tensile strength is a simple method used to estimate the tensile strength of concrete that considered very difficult to estimate by using the direct tension test due to the brittle nature of concrete. Both modulus of elasticity and splitting tensile strength are usually estimated as a function of concrete compressive strength. [1, 2]

As new types of concrete appear, further investigation for their mechanical properties are needed, one of these types is the reactive powder concrete as a type of ultra high performance concrete having a dense and durable composite mix generally characterized by low water/cement ratio, high cement content and in most cases containing steel fibers [3]. The strength of reactive powder concrete is highly affected by its contents especially the amount of the steel fibers that is usually added as a volumetric ratio, the increase in this ratio will reflect positively on the modulus of elasticity, compressive strength, splitting tensile strength and modulus of rupture $[3,4]$.

\section{Static modulus of elasticity and splitting tensile strength of concrete}

Concrete is a composite material consisting of materials of different sizes and properties, each material has a different modulus of elasticity, thus the modulus of elasticity of concrete is highly dependent on its components properties.

A conventional basic form Eq. (1) was adopted by many provisions to establish concrete modulus of elasticity as a function of concrete compressive strength.[5]

$$
E c=a \cdot\left(f_{c}^{\prime}\right)^{b} \gamma^{c}
$$

Where:

$\mathrm{Ec}=$ modulus of elasticity

$\left(\mathrm{f}_{\mathrm{c}}^{\prime}\right)=$ specified concrete compressive strength

$\gamma=$ unit weight of concrete

$\mathrm{a}, \mathrm{b}$ and $\mathrm{c}=$ non-dimensional coefficient

To reach at a final form of this formula which can be applied for concrete design purposes, a regression analysis must be done to establish the values of $a, b$ and c parameters. This equation reflects the effects and the mechanical properties of materials that are used in concrete production as well as air content in the fresh mix, unit weight, curing procedure and heat temperature and the age of test on the modulus of elasticity[5].

\footnotetext{
Corresponding author: dr eyad alhachamee@yahoo.com
} 
In the same way, the splitting tensile strength of concrete is mainly dependent on the compressive strength as many provisions and previous researches adopted formulas which can be represented in Eq. (2). This basically reflects the effects of original materials used in concrete production represented in terms of concrete compressive strength $[6,7]$.

$$
f_{c t}=k \sqrt{f_{c}^{\prime}}
$$

Where:

$\mathrm{f}_{\mathrm{ct}}=$ splitting tensile strength of concrete

$\mathrm{f}_{\mathrm{c}}^{\prime}=$ specified concrete compressive strength

$\mathrm{k}=$ non-dimensional coefficient may found by regression analysis

These equations used in concrete design calculation in order to estimate the modulus of elasticity and the splitting tensile strength are essentially derived for conventional concrete. In case of ultra-high performance concrete like reactive powder concrete most of these equations need re-examination to make them more suitable and representative for the new concrete types. The use of different types of additives, like cementitious materials, pozolanic materials and steel fibers significantly improve the strength of concrete. The addition of steel fibers mainly enhance the flexural strength and the tensile strength of concrete and in less manner the compressive strength. The presence of steel fibers in concrete has a positive impact on crack resistance, where cracks are prevented from forming and the formation of additional cracks gets delayed after the first crack appears [8].

\section{Previous provisions}

Over the years several specifications and researchers try to estimate the mechanical properties of concrete such as modulus of elasticity, splitting tensile strength and flexural strength. As the concrete manufacturing evolved producing new types of concrete, new formulas were proposed to simulate the new types of concrete.

- The ACI-318M-14[9] estimates the modulus of elasticity and the splitting tensile strength of normal concrete as a function of concrete compressive strength ;Eq.(3) and Eq.(4):

$$
\begin{aligned}
& E_{c}=4700 \sqrt{f_{c}^{\prime}} \\
& f_{c t}=0.56 \sqrt{f_{c}^{\prime}}
\end{aligned}
$$

- As the reactive powder concrete become more recognizable, H. M. Al-Hassani et. al.[10] try to give a better estimation for the modulus of elasticity based on regression analysis as in Eq.(5)

$$
E_{c}=113.43\left(f_{c}^{\prime}\right)+31126.74
$$

- N. Arioglu et. al [7] proposed an equation to calculate the splitting tensile strength for high strength concrete containing different types of additives (silica fume and fly ash), this equation (Eq.(6)) is applicable for concrete compressive strength up to $120 \mathrm{MPa}$ with maximum curing temperature of $30 \mathrm{C}^{\circ}$.

$$
f_{c t}=0.387\left(f_{c}^{\prime}\right)^{0.63}
$$

Where:

$\mathrm{f}_{\mathrm{ct}}=$ splitting tensile strength of concrete

\section{Experimental program}

\subsection{Material properties:}

As the properties of the materials have major effects on the reactive powder concrete strength; the types, properties and specification matching these materials can be summarized as follows:

1- Cement: ordinary portland cement type I produced by Mass Iraq Company are used in this work to produce RPC. The physical and chemical properties of cement agreed with the Iraqi specification NO.5/1984[11].

2- Fine sand: Fine quartz sand with particle size of 300 $\mu \mathrm{m}-600 \mu \mathrm{m}$ from DCP (Don Construction Products) is used in this work. The specific gravity and the sulfate content of this sand are matching the requirements of the Iraqi specification NO.45/1984[12].

3- Tap water is used in RPC production (mixing and curing).

4- Silica fume: Silica fume is an extremely fine powder. Its particles are several times smaller than cement and are usually used to enhance the strength of concrete. Silica fume (MEYCO MS610) from BASF Company is used as a percentage of cement by weight with several different percentages in this work. The physical and chemical properties agreed with ASTM C1240[13] requirements.

5- Superplasticizer: represented by ViscoCrete -5930 provided from Sika is used to enhance the workability of fresh reactive powder concrete paste, the properties of this admixture satisfy the requirements of ASTM C494[14].

6- Steel fibers: Micro steel fiber $15 \mathrm{~mm}$ in length, 0.2 $\mathrm{mm}$ in diameter, aspect ratio of 75 and tensile strength of $2850 \mathrm{MPa}$, is used in four different volumetric ratios varying from $0 \%$ to $2 \%$.

\subsection{Concrete: mix design parameters, casting and curing}

In this work six mixes of reactive powder concrete has been made, the content of cement and fine quartz sand is constant for all mixes with $900 \mathrm{~kg} / \mathrm{m} 3$ and $990 \mathrm{~kg} / \mathrm{m}^{3}$ respectively. Silica fume is used as a weight percentage of cement in four different ratios $(12 \%, 15 \%, 20 \%$ and $25 \%$ ). Also, four volumetric ratios (Vf) of the steel fibers $(0 \%, 1 \%, 1.5 \%$ and $2 \%)$ are used. The content of water represented by w/c ratio varies from $16 \%$ to $22 \%$. A 
steady content of $6 \%$ for ViscoCrete-5930 superplasticizer is used for all mixes.

Cylindrical specimens with diameter of $150 \mathrm{~mm}$ and height of $300 \mathrm{~mm}$ are made cured and tested to find the compressive strength, the modulus of elasticity and the splitting tensile strength of reactive powder concrete mixes, and all specimens are cured in tap water for 28 days.

\subsection{Experimental evaluation of compressive strength, modulus of elasticity and splitting tensile strength}

The compressive strength and splitting tensile strength of reactive powder concrete were evaluated by tests carried out on cylinders $(150 \mathrm{~mm} \times 300 \mathrm{~mm})$, these tests are performed according to ASTM C39[15] and ASTM C496[16] respectively. All cylindrical specimens were loaded up to failure by using hydraulic digital test machine with maximum capacity of $4000 \mathrm{kN}$.

To estimate the static modulus of elasticity ASTM C469[17] specification was adopted, a percentage of $40 \%$ of the predicted ultimate concrete compressive strength was applied during the test of the cylindrical specimens of $(150 \mathrm{~mm} \times 300 \mathrm{~mm})$.

\section{Tests results and discussion}

Several tests were carried out on the cylindrical specimens to find the compressive strength, splitting tensile strength and the modulus of elasticity where the following results are found:

- Compression tests were carried out on cylinders at age of 28 days to estimate the compressive strength of different mixes made with reactive powder concrete, the test results show that the content of silica fume and the $\mathrm{w} / \mathrm{c}$ ratio have major effects on the compressive strength, and in less manner steel fibers content. Six mixes with three compressive strength targets $70 \mathrm{MPa}, 80 \mathrm{MPa}$ and $90 \mathrm{MPa}$ were examined to evaluate the influence of changes in silica fume and steel fibers content as well as w/c ratio on the reactive powder compressive strength. As the silica fume content increased from $20 \%$ to 25\% (mixes M1-70 and M2-80) the concrete strength increased from 81.292 $\mathrm{MPa}$ to $84.3 \mathrm{MPa}$ for constant $\mathrm{w} / \mathrm{c}$ ratio of $22 \%$. While, in order to get a target compressive strength of $90 \mathrm{MPa}$ (mix M3-90) w/c was decreased to $20 \%$ which produced the compressive strength of $99.5 \mathrm{MPa}$. These results indicate that the silica fume and water content share the greatest effects on reaching compressive strength targets. A lesser effect of steel fibers can be noticed, as the steel fibers content increased from $1 \%$ to $1.5 \%$ and $2 \%$ silica fume content can be decreased from $20 \%$ to $15 \%$ and $12 \%$ to keep the strength in the designed target range. The mix M4-0 with no steel fiber has high silica fume content of $25 \%$ and a less $\mathrm{w} / \mathrm{c}$ ratio is used to get a compressive strength of $76.682 \mathrm{MPa}$. Table (1) shows the results of mechanical properties for all mixes experimentally examined in this work and Fig. (1) shows the cylindrical specimens during and after the test. The effect of silica fume and steel fibers on reactive powder properties were examined, and the gain of silica fume can be noticed not only by its pozzolanic effects but by increasing mix density and enhancing the bond strength between the fine materials and the steel fibers[18].

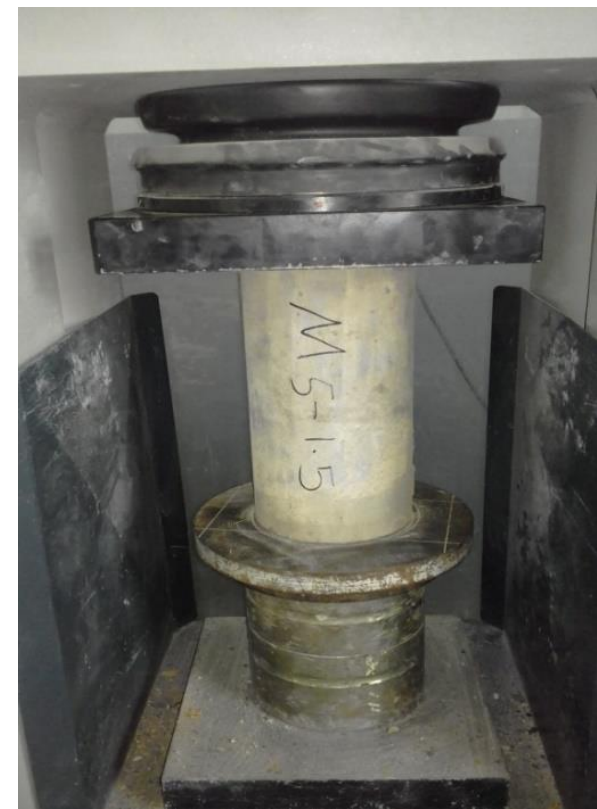

a)At test starting

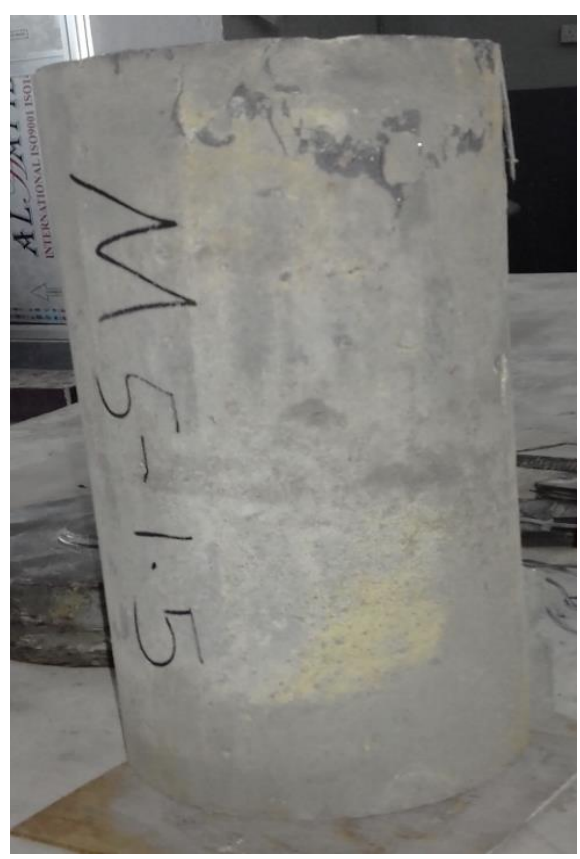

b)After the test

Fig. 1. Cylindrical specimen under compression test 
- The splitting tensile strength is highly affected by the changes in the volumetric ratio of steel fibers, as the steel fibers content increases from $0 \%$ to $1 \%, 1.5 \%$ and $2 \%$ the splitting tensile strength increased from 4.033 $\mathrm{MPa}$ to $9.609 \mathrm{MPa}, 11.944 \mathrm{MPa}$ and 12.896 $\mathrm{MPa}$ respectively. This enhancement in tensile strength with the increase in steel fibers content occurred because steel fibers resist and delay the formation of the cracks, and permit the transmission of stresses through cracks[19]. On the other hand, the changes in silica fume content has a slight effect on the splitting tensile strength, see Table (1). Fig.(2) shows the failure mode for specimen with and without steel fibers respectively.

- The increase in silica fume from $12 \%$ to $15 \%, 20 \%$ and $25 \%$ provide some noticeable enhancement in modulus of elasticity production, as shown in Table(1).

- The relationship between modulus of elastic and steel fibers content is not clear. Where the increase in steel fibers show a little improvement in the modulus of elasticity (for example mix M4-0 through M6-2) this can be explained from the procedure used in modulus of elasticity predication itself as the percentage of $40 \%$ from the ultimate concrete compressive strength is adopted, in most cases the estimation of modulus of elasticity at this ratio ends before the crack stage, while steel fibers act when cracks start to form and beyond[10].

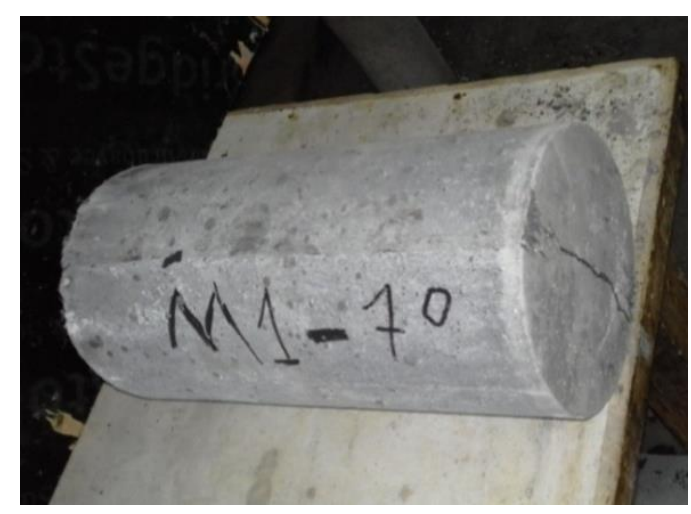

a) With steel fibers

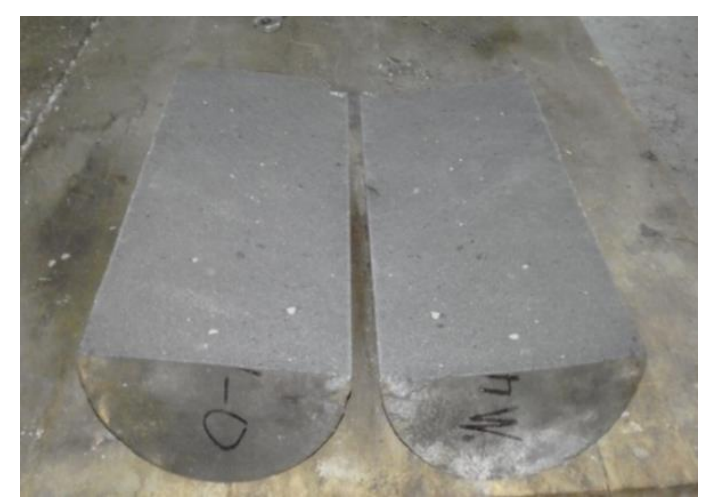

b) Without steel fibers

Fig. 2 .Splitting tensile strength failure mode

\section{Data analysis and proposed equations}

In this work two equations are proposed to predict the modulus of elasticity and the splitting tensile strength based on data obtained experimentally from this work and data provided from previous works by applying regression analysis:

a) Static modulus of elasticity: As the modulus of elasticity mainly depends on the compressive strength, a regression analysis was applied on the basic form Eq.(1) based on the available data from this work and other previous works Table(1) and Table(2) respectively which is made of reactive powder concrete, the proposed equation (Eq.(7)) was found to be more suitable and representative for reactive powder concrete behavior and try to be more reflective of its components properties and adopted a new power for the compressive strength of 0.25 .

$$
E_{c}=14000\left(f_{c}^{\prime}\right)^{0.25}
$$

The coefficient of variation (COV) used to make a comparison of results, where the proposed equation gives a COV of $10.677 \%$ and a mean value of 1.001 , which can be considered better than other approaches discussed in this work, Table(3) show the modulus of elasticity results for all methods studied in this work. Also, Fig.(3) illustrates the relationship between the modulus of elasticity experimentally estimated to the calculated modulus of elasticity (Ec test/Ec calculated) and the concrete compressive strength (MPa). Fig.(4) shows a comparison between the three approaches adopted in this work, where the proposed equation shows the best convergence of the test to predicted modulus of elasticity ratio.

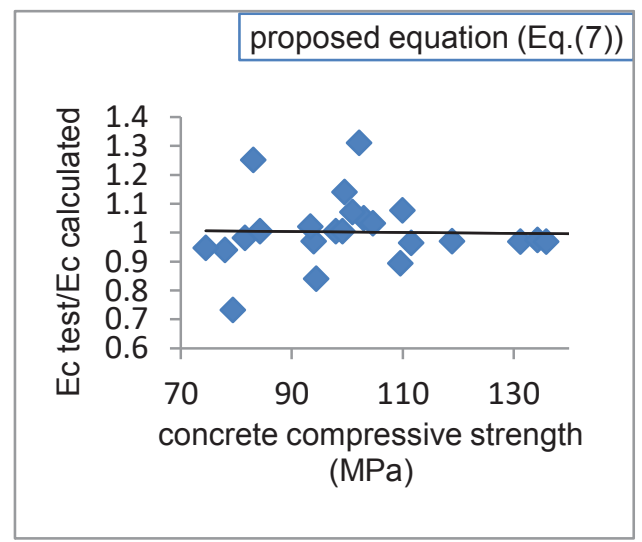

a) Proposed equation (Eq.7) 


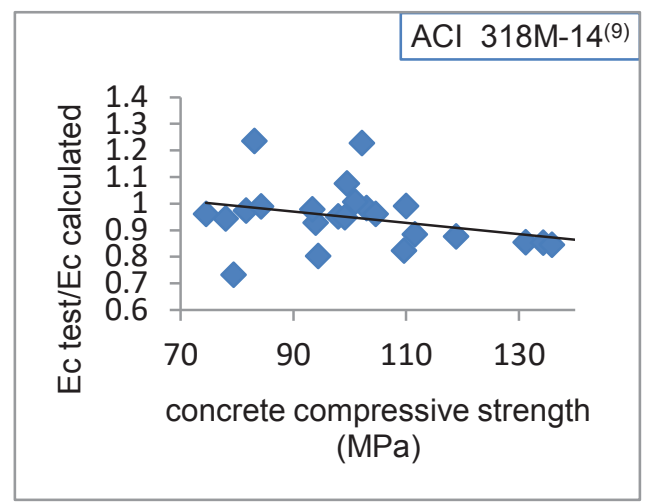

b) ACI $318 \mathrm{M}-14$

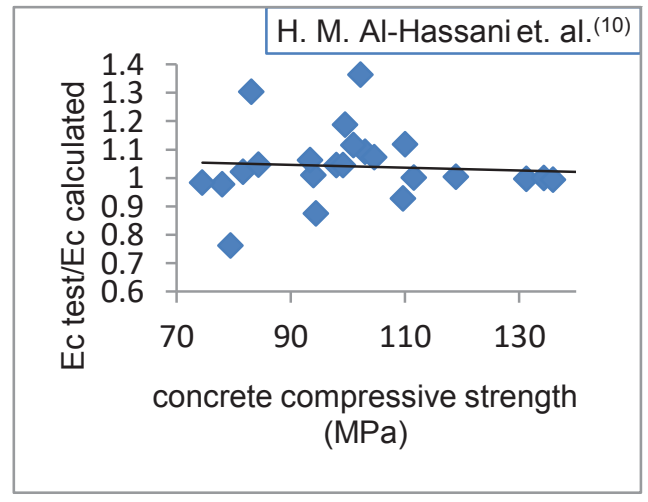

c) H. M AL-Hassani et. al. equation

Fig. 3. Relationship between (Ec test/Ec calculated) and concrete compressive strength (MPa)

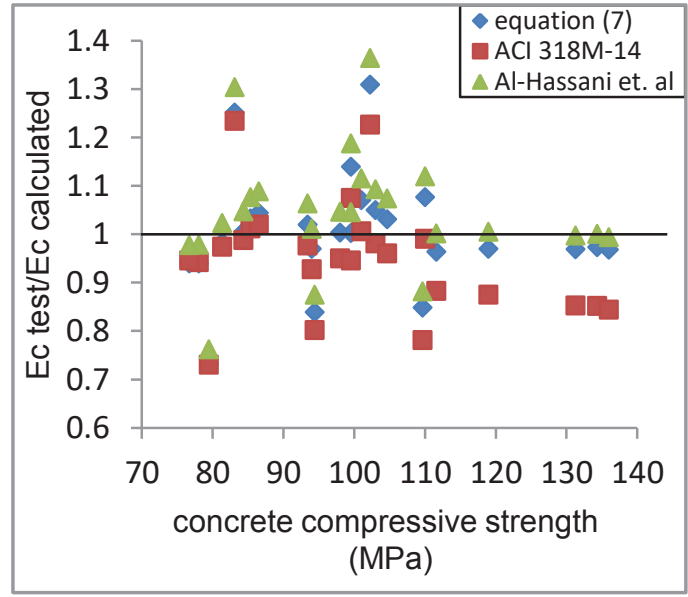

Fig. 4. Comparison of (Ec test/Ec calculated) for all approaches

\section{b) Splitting tensile strength:}

In the same way as in the modulus of elasticity estimation, a new formula for splitting tensile strength of reactive powder concrete is derived Eq. (8):

$$
f_{c t}=0.1\left(f_{c}^{\prime}\right)^{0.85}
$$

Besides the new power of compressive strength, and due to the vital role of steel fibers presence in strengtheingn the reactive powder concrete against the tensile stresses a new term based on the content of the steel fibers is added as in Eq.(9).

$$
f_{c t}=0.1\left(f_{c}^{\prime}\right)^{0.85}+3.6 V_{f}
$$

The proposed equation gives a COV of $10.455 \%$ and a mean value of 1.204 , which is considered much better than the ACI-318M -14 with COV of 26.206 and Arigula equation with $\mathrm{COV}$ of $25.828 \%$. Table(4) shows the splitting tensile strength for all approaches and Fig.(5) illustrates the relationship between the ratio of splitting tensile strength taken from test results to the calculated ones and the steel fibers content (Vf \%). From this figure, a straight line is provided by the proposed method (Eq.(9)), while the other two methods tend to be highly unconservative as the steel fibers content increased, this behavior occurred due to the negligence of the effects of steel fibers by the other methods. Fig.(6) shows the comparison of the ratio of ( $f_{c t}$ test $/ f_{c t}$ calculated $)$ for the proposed equation (eq.(9)) and the other methods that discussed in this work, equation (9) shows a good agreement between the experimental and theoretical splitting tensile strength value.

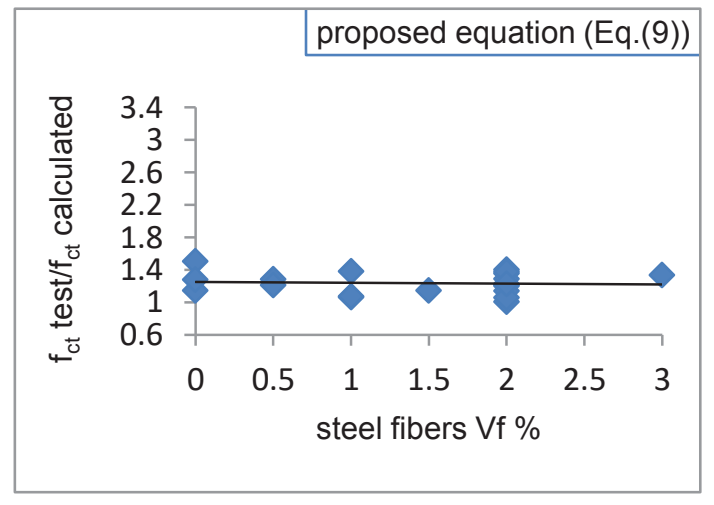

a) proposed equation (Eq.(9))

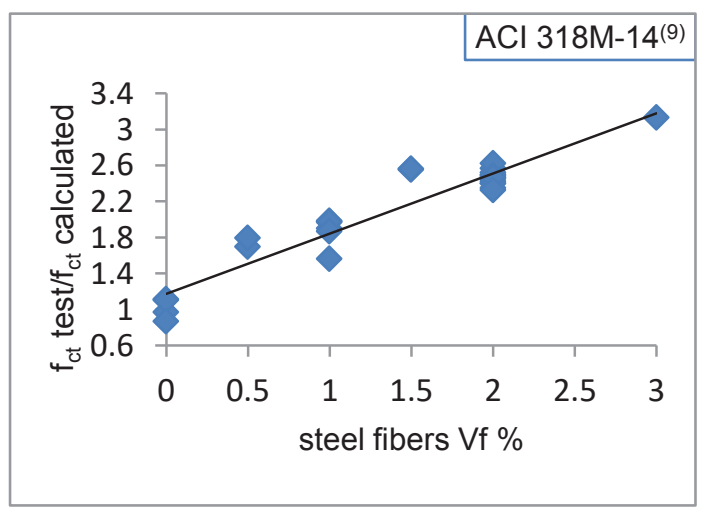

b) $\mathrm{ACI} 318 \mathrm{M}-14$ 


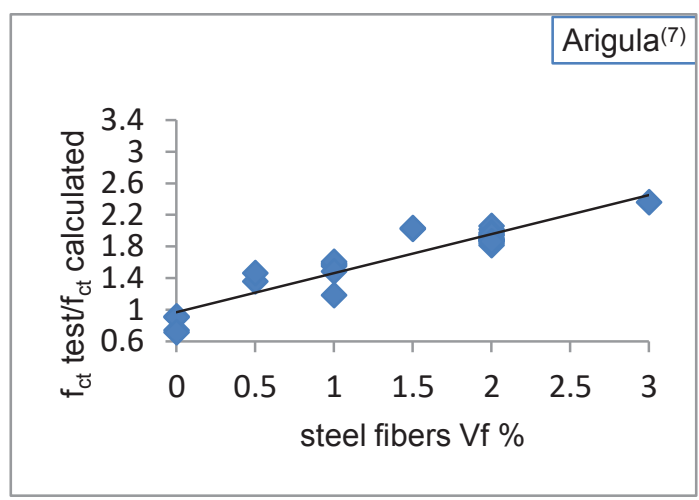

c) Arigula et. al. equation

Fig. 5 . Relationship between (fct test/fct calculated) and steel fibers content (MPa)

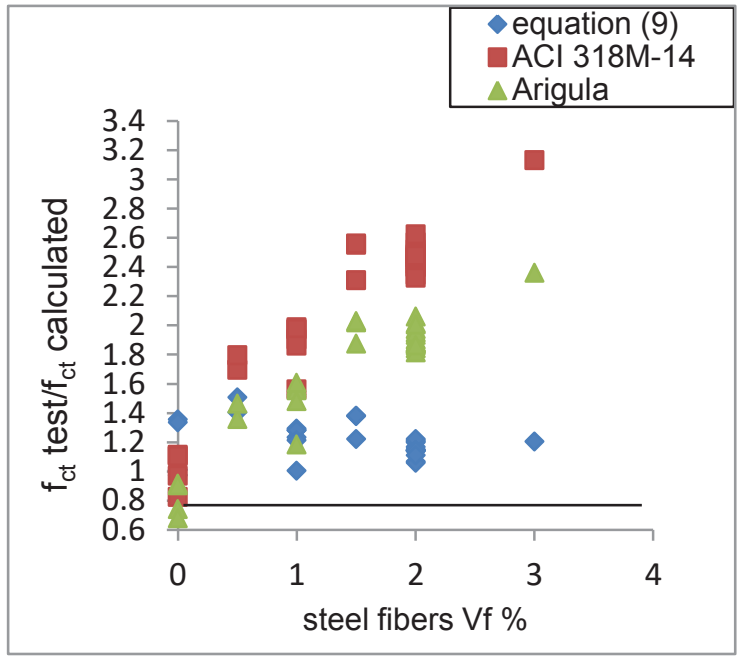

Fig. 6. Comparison of $\left(f_{c t}\right.$ test $/ f_{c t}$ calculated $)$ for all approaches

\section{Conclusions:}

From the above results the following facts can be concluded:

1. The splitting tensile strength is highly affected by the presences of steel fibers, the experimental results show that the increase in steel fibers from $0 \%$ to $1 \%$, $1.5 \%$ and $2 \%$ lead to increase in splitting tensile strength from $4.033 \mathrm{MPa}$ to $9.609 \mathrm{MPa}, 11.944 \mathrm{MPa}$ and $12.896 \mathrm{MPa}$ respectively.

2. Fewer effects on the splitting tensile strength can be noticed as the compressive strength changes with a constant ratio of steel fibers, as the compressive strength increases from 81.292 $\mathrm{MPa}$ to $84.3 \mathrm{MPa}$ and 99.5 $\mathrm{MPa}$ the splitting tensile strength slightly increases from 9.609 $\mathrm{MPa}, 10.148 \mathrm{MPa}$ and 10.362 MPa respectively.

3. The proposed equation (Eq. (9)) that was used to predict the splitting tensile strength of reactive powder concrete focused on the effects of steel fibers. This equation shows a good agreement with the experimental test results. The COV provided by this equation is $10.398 \%$ and less than the other two approaches examined in this work (ACI-14 and Arigula) with $\mathrm{COV}$ of $26.944 \%$ and $25.828 \%$ respectively.

4. The modulus of elasticity slightly affected by the presence of steel fibers, this behavior probably occurred due to the adopted test procedure where $40 \%$ from the ultimate concrete compressive strength is adopted to estimate the modulus of elasticity.

5. Generally, the strength of reactive powder is mainly dependent on the content of steel fibers, silica fume, $\mathrm{w} / \mathrm{c}$ ration and the finesses of its contents.

\section{References:}

1. B. Haranki, MS.c. thesis, University of florida, (2009)

2. T. Noguchi, F. Tomosawa, K. M. Nemati, B. M. Chiaia, A. P. Fantilli, ACI structural Journal 106, 5, 690-696 September-October (2009)

3. B. Bae, H. Choi, B. Lee, C. Bang, Advances in Materials Science and Engineering Journal, (2016)

4. H. Yazici, M. Yardimci, S. Aydin A. S. Karabulut, Construction and Building Materials 23, 1223-1231 (2009)

5. F. Tomosawa and T. Noguchi, Journal of Structural and Construction Engineering 60, 474, 1-10 (1995)

6. K. A. Gajendran, R. Anuradha G. S. Venkatasubramani, ARPN Journal of Engineering and Applied Sciences 10, 14, (August 2015)

7. N. Arioglu, Z. C. Girgin, E. Arioglu, ACI Materials Journal 103, 1, (January-February 2006)

8. M. K. Maroliya, International Journal of Engineering Research and Development 4, Issue 4, 58-61 (October 2012)

9. ACI Committee 318," Building Code Requirements for Reinforced Concrete and Commentary -ACI 318RM-14", American Concrete Institute, Detroit, pp. 432, 2014.

10. H. M. Al-Hassani, W. I. Khalil, L. S. Danha, Eng. \&Tech. Journal 31 Part (A), 16 (2013)

11. Iraqi Specification, No. 5/1984, "Portland Cement", Ministry of Planning, Central Organization for Standardization and Quality Control.

12. Iraqi Specification, No.45/1984, "Aggregate from Natural Sources for Concrete and Construction", Ministry of Planning, Central Organization for Standardization and Quality Control.

13. ASTM C 1240-05, "Standard Specification for the Use of Silica Fume as a Mineral Admixture in Hydraulic Cement Concrete, Mortar, and Grout", Vol. 04.02, 1-7 (2005)

14. ASTM C 494 /C 494M-05a, "Standard Specification for Chemical Admixtures for Concrete", Vol. 04.02, 1-11 (2005)

15. ASTM C39/C39M- 05, "Standard Test Method for Compressive Strength of Cylindrical Test Specimens", Vol. 04.02, 1-9 (2005)

16. ASTM C496/C496M-04, "Standard Test Method for Splitting Tensile Strength of Cylindrical Concrete 
Specimens", Vol. 04.02, 1-5 (2005)

17. ASTM C469-02, "Standard Test Method for Static Modulus of Elasticity and Poisson's Ratio of

Concrete in Compression", Vol. 04.02, 1-7 (2005)

18. A.M. Neville, Pearson Education Limited, Fourth and Final Edition, p.844 (2005)

19. S.P. Yaakoub, Ph.D. thesis, University of

Technology, Baghdad, 2010.

20. M. M. Saeed., Ph.D. thesis, University of Technology, Baghdad, 2010.

Table 1. Test results of mechanical properties experimentally examined in this work

\begin{tabular}{|c|c|c|c|c|c|c|c|}
\hline NO. & Mix & $\begin{array}{c}\text { Steel fibers } \\
\mathrm{V}_{\mathrm{f}}\end{array}$ & $\begin{array}{c}\text { Silica } \\
\text { fume }\end{array}$ & $\begin{array}{c}\mathrm{w} / \mathrm{c} \\
\text { ratio }\end{array}$ & $\begin{array}{c}\text { Compressive strength } \\
\left(f_{c}^{\prime}\right) \mathrm{MPa}\end{array}$ & $\begin{array}{c}\text { splitting tensile } \\
\text { strength }\left(f_{c t}\right) \\
\mathrm{MPa}\end{array}$ & $\begin{array}{c}\text { modulus of } \\
\text { elasticity } \\
(\mathrm{Ec}) \\
\mathrm{MPa}\end{array}$ \\
\hline 1 & $\mathrm{M} 1-70$ & $1 \%$ & $20 \%$ & 0.22 & 73.214 & 9.609 & 41286.951 \\
\hline 2 & $\mathrm{M} 2-80$ & $1 \%$ & $25 \%$ & 0.22 & 84.301 & 10.148 & 42617.255 \\
\hline 3 & $\mathrm{M} 3-90$ & $1 \%$ & $20 \%$ & 0.20 & 96.500 & 10.362 & 44327.260 \\
\hline 4 & $\mathrm{M} 4-0$ & $0 \%$ & $25 \%$ & 0.16 & 72.462 & 4.033 & 38924.274 \\
\hline 5 & $\mathrm{M} 5-1.5$ & $1.5 \%$ & $15 \%$ & 0.22 & 73.936 & 11.944 & 43924.827 \\
\hline 6 & $\mathrm{M} 6-2$ & $2 \%$ & $12 \%$ & 0.22 & 74.804 & 12.896 & 44568.264 \\
\hline
\end{tabular}

Table 2. Mechanical properties available from previous works

\begin{tabular}{|c|c|c|c|c|c|c|c|}
\hline No. & Mix & $\begin{array}{l}\text { Silica } \\
\text { fume } \%\end{array}$ & $\begin{array}{c}\text { Steel } \\
\text { fibers }\left(\mathrm{V}_{\mathrm{f}}\right) \\
\%\end{array}$ & $\begin{array}{c}\text { Compressive } \\
\text { strength }\left(f_{c}^{\prime}\right) \\
\mathrm{MPa}\end{array}$ & $\begin{array}{l}\text { Splitting tensile } \\
\text { strength } \\
\mathrm{MPa}\end{array}$ & $\begin{array}{l}\text { modulus of } \\
\text { elasticity } \\
\mathrm{MPa}\end{array}$ & $\begin{array}{l}\text { Ref. } \\
\text { No. }\end{array}$ \\
\hline 1 & MSP-N & 15 & 2 & 118.91 & 14.78 & 44841 & 10 \\
\hline 2 & MSF0 & 0 & 2 & 111.6 & 15.19 & 43836 & 10 \\
\hline 3 & MSF10 & 10 & 2 & 131.27 & 15.4 & 45900 & 10 \\
\hline 4 & MSF15 & 15 & 2 & 134.33 & 15.9 & 46398 & 10 \\
\hline 5 & MSF20 & 20 & 2 & 146.19 & 16.23 & 47422 & 10 \\
\hline 6 & MSF25 & 25 & 2 & 149.39 & 17.25 & 48295 & 10 \\
\hline 7 & MSF30 & 30 & 2 & 157.48 & 17.55 & 49103 & 10 \\
\hline 8 & MFR0 & 25 & 0 & 135.93 & 6.32 & 46262 & 10 \\
\hline 9 & MFR1 & 25 & 1 & 144.57 & 10.5 & 47363 & 10 \\
\hline 10 & MFR3 & 25 & 3 & 151.62 & 21.59 & 48538 & 10 \\
\hline 11 & M0.0-15 & 15 & 0 & 78 & 5.5 & 39100 & 20 \\
\hline 12 & M0.5-15 & 15 & 0.5 & 94 & 9.2 & 42250 & 20 \\
\hline 13 & M1.0-15 & 15 & 1 & 98 & 11 & 44200 & 20 \\
\hline 14 & M1.5-15 & 15 & 1.5 & 103 & 14.5 & 46800 & 20 \\
\hline 15 & M2.0-15 & 15 & 2 & 110 & 15.4 & 48800 & 20 \\
\hline 16 & M2.0-10 & 10 & 2 & 101 & 14 & 47500 & 20 \\
\hline 17 & M2.0-17 & 5 & 2 & 93.4 & 12.7 & 44370 & 20 \\
\hline 18 & M0 & 15 & 0 & 79.42 & 5.5 & 30578 & 19 \\
\hline 19 & M0.5 & 15 & 0.5 & 83.11 & 9.16 & 52885 & 19 \\
\hline 20 & M1 & 15 & 1 & 99.53 & 11.01 & 50379 & 19 \\
\hline 21 & M1.5 & 15 & 1.5 & 102.2 & 14.49 & 58265 & 19 \\
\hline 22 & M2 & 15 & 2 & 109.65 & 14.44 & 38432 & 19 \\
\hline 23 & Msf10 & 10 & 2 & 104.66 & 14.14 & 46171 & 19 \\
\hline 24 & Msf5 & 5 & 2 & 94.41 & 12.66 & 36618 & 19 \\
\hline
\end{tabular}


Table 3. Modulus of elasticity calculated by several methods

\begin{tabular}{|c|c|c|c|c|c|}
\hline Method & COV. \% & $\begin{array}{c}\text { Ec test/Ec calculated mean } \\
\text { (average) }\end{array}$ & Min. & Max. & Max./Min. \\
\hline Proposed equation Eq.(7) & 10.677 & 1.001 & 0.732 & 1.309 & 1.788 \\
\hline ACI $318 \mathrm{M}-14^{(9)}$ & 12.419 & 0.932 & 0.73 & 1.234 & 1.690 \\
\hline H. M. Al-Hassani ${ }^{(10)}$ & 10.904 & 1.038 & 0.762 & 1.364 & 1.790 \\
\hline
\end{tabular}

Table 4. Splitting tensile strength calculated by several methods

\begin{tabular}{|c|c|c|c|c|c|}
\hline Method & COV. $\%$ & $\begin{array}{c}\mathrm{f}_{\text {tsp }} \text { test } / \mathrm{f}_{\text {tsp }} \text { calculated mean } \\
\text { (average) }\end{array}$ & Min. & Max. & Max./Min. \\
\hline Proposed equation Eq.(9) & 10.455 & 1.204 & 0.971 & 1.506 & 1.551 \\
\hline ACI $318 \mathrm{M}-14^{(9)}$ & 26.206 & 2.125 & 0.867 & 3.131 & 3.611 \\
\hline Arigula $^{(7)}$ & 25.266 & 1.673 & 0.716 & 2.359 & 3.295 \\
\hline
\end{tabular}

